\title{
Impaired Incentive Learning in Treated Parkinson's Disease
}

\author{
D. Charbonneau, R.J. Riopelle and R.J. Beninger
}

\begin{abstract}
Objective: To quantify the performance of patients with Parkinson's disease (PD) in incentive learning, or learning to respond to stimuli that signal the imminent presentation of a reinforcer, and in paired-associate learning, or learning of word associations. Methods: The performance of 32 patients with idiopathic PD was compared to that of 25 healthy control subjects, and 32 subjects suffering from arthritis, matched for age and education. The PD and arthritic groups were comparable on a self-report measure of physical disability. All subjects were physically capable of satisfying the contingencies of the incentive learning task. The avoidance task that quantified incentive learning used money loss as an aversive stimulus. The word paired-associate learning task was presented on a computer and feedback was not given on performance. Results: The normal and arthritic groups performed equally well on the avoidance task, whereas the PD group was impaired despite dopaminergic replacement therapy. The groups did not differ significantly in paired-associate learning. Conclusions: These findings are among the first to suggest that the nigrostriatal dopamine dysfunction associated with PD may play a role in incentive learning but not in paired-associate learning and are consistent with a role for dopamine in certain forms of learning and memory. The findings may highlight differences between tonic and modulated function in the nigrostriatal system.
\end{abstract}

RÉSUMÉ: Atteinte de l'apprentissage motivé par un renforcement chez les parkinsoniens traités. Objectif: Le but de l'étude était de quantifier la performance de patients atteints de la maladie de Parkinson (MP) quant à l'apprentissage motivé par un renforcement, ou apprentissage en réponse à des stimuli qui signalent la présentation imminente d'un renforcement, et l'apprentissage de paires associées, ou apprentissage d'associations de mots. Méthodes: Nous avons comparé la performance de 32 patients atteints de MP idiopathique à celle de 25 sujets contrôles sains et de 32 sujets atteints d'arthrite, appariés pour l'âge et l'éducation. Les groupes atteints de MP et d'arthrite étaient comparables quant à l'incapacité physique selon une échelle d'auto-évaluation. Tous les sujets étaient physiquement capables de satisfaire aux contingences de la tâche de l'apprentissage motivé par un renforcement. La tâche d'évitement pour quantifier l'apprentissage motivé par un renforcement utilisait la perte d'argent comme stimulus aversif. La tâche d'apprentissage par paires associées était présentée sur un ordinateur et aucune information n'était fournie au sujet sur sa performance pendant le test. Résultats: Les groupes normaux et arthritiques ont également bien réussi la tâche d'évitement, alors que la performance du groupe MP était altérée malgré une thérapie de remplacement dopaminergique. Les groupes n'étaient pas significativement différents dans les tâches d'apprentissage par paires associées. Conclusions: Ces observations sont parmi les premières à suggérer que la dysfonction dopaminergique nigrostriée associée à la MP pourrait jouer un rôle dans l'apprentissage motivé par un renforcement mais pas dans l'apprentissage par paires associées et sont compatibles avec le fait que la dopamine puisse jouer un rôle dans l'apprentissage et la mémoire. Ces observations illustrent les différences entre les fonctions toniques et modulées dans le système nigrostrié.

Can. J. Neurol. Sci. 1996; 23: 271-278

Parkinson's disease (PD) is associated primarily with the degeneration of dopaminergic neurons originating in the substantia nigra pars compacta that innervate the striatum. The rationale for the present study emerged from animal studies demonstrating that dopamine dysfunction, besides influencing the control of locomotor activity, can affect incentive motivational learning, namely the shaping of behaviour by rewarding stimuli. ${ }^{1,2}$ In animal studies, dopamine dysfunction did not appear to play a critical role in the learning of relationships among stimuli, or simple stimulus-stimulus associative learning, which occurs when stimuli are presented in close temporal contiguity without reinforcement. $1,3,4$

Historically, the neural circuitry of reward-related learning has been associated with the dopaminergic mesolimbic pathway (see Ref 5). Recently, however, the nigrostriatal pathway also has been implicated. ${ }^{6-8}$ With respect to stimulus-stimulus associative learning, several studies have shown that animals with a dopamine dysfunction in either or both pathways can learn the association between stimuli that co-occur (see Ref 1).

The distinction between an impairment in locomotor activity and an impairment in incentive motivational learning may not be readily apparent, as both can result from a dopamine dysfunction. Operant avoidance tasks have often been used with animals

From the Departments of Psychology (D.C., R.J.B.), Medicine (R.J.R.), and Psychiatry (R.J.B.), Queen's University, Kingston.

RECEIVED DECEMBER 6, 1995. ACCEPTED IN FINAL FORM MAY 3, 1996

Reprint requests to: Dr. R.J. Beninger, Department of Psychology, Queen's University, Kingston, Ontario, Canada K7L 3N6 
and occasionally with different human populations (see for instance Refs 9-12). They allow for the distinction between the effects of a motor impairment and the effects of impairments in incentive learning. Indeed, selective deficits in avoidance responses (that prevent the onset of an aversive stimulus) are indicative of impaired incentive learning whereas deficits in escape responses (that terminate an aversive stimulus) may reflect a motor dysfunction. This is especially true when the motor requirements of the avoidance and escape responses are identical. $^{13}$

Incentive learning is also known as habit learning which Salmon et al. ${ }^{14}$ defined as "... the formation of simple associations in which a neutral stimulus comes to elicit a certain motor response as a function of repeated reinforcement" (p.185). Procedural memory involves the unconscious acquisition of information, such as skill learning, habit formation, non-associative learning, classical conditioning, ${ }^{15}$ and possibly active avoidance learning, a form of operant conditioning. ${ }^{16} \mathrm{~A}$ number of animal and human studies suggest that the basal ganglia are critical for the acquisition of procedural knowledge (e.g., Refs. 1516). Furthermore, habit learning is thought to depend on the integrity of the striatum. ${ }^{14}$

The extent to which the role of a neurochemical system in behavior can be extrapolated from animals to humans depends in major part on the comparability of the tests used. ${ }^{17}$ Previous investigations of incentive learning in humans have used an operant avoidance task in which the offset of an aversive stimulus is rewarding. Fischman and her colleagues ${ }^{18.19}$ investigated the effects of a dopamine receptor antagonist drug on healthy human volunteers, and found that avoidance responses were inhibited at doses that failed to affect escape responses. In other words, subjects did not respond to prevent the onset of the aversive stimulus but responded to turn the aversive stimulus off. Using a similar money-loss avoidance task, Cutmore and Beninger ${ }^{9}$ showed that schizophrenic subjects treated with dopamine receptor antagonists were impaired on avoidance responses but not on escape responses. The level of impairment was positively correlated with the level of dopamine receptor blockade as indicated by blood prolactin levels. These subjects also showed a deficit in stimulus-stimulus associative learning but it did not correlate with indices of dopaminergic function. Results were consistent with those from animal studies and implicated dopamine in incentive but not stimulus-stimulus associative learning.

The present study evaluated individuals with PD on dopaminergic replacement therapy. For many years, the emphasis in PD has been on motor deficits. Recent studies have shown the presence of cognitive deficits is PD as well. The present study suggests that an impairment of incentive learning may contribute to both motor and cognitive dysfunctions. This is the first study to examine the hypothesis that the dopaminergic dysfunction observed in PD may lead to reduced performance on tests of incentive learning, but not on tests of stimulus-stimulus associative learning. In other words, PD patients may recognize associations among stimuli, but may have a reduced ability to respond to reward-related incentive stimuli, not only because of physical restrictions, but also because of an impairment in incentive learning. This study assessed PD patients, age- and education-matched control subjects without a central dopaminergic deficiency but with comparable physical disabilities, and age- and education-matched physically healthy subjects on incentive learning and stimulus-stimulus associative learning tasks. It was expected that PD patients would be impaired on an operant avoidance task, a measure of incentive learning, relative to the comparison groups, but not on a paired-associate task, which measured stimulus-stimulus associative learning.

\section{Methods and Materials}

\section{Subjects}

Forty-five patients with a diagnosis of idiopathic PD were recruited from a regional Movement Disorder Clinic. Only PD patients displaying motor improvement when taking antiparkinsonian medication, such as deprenyl, levodopa, and/or bromocriptine, were included and testing was carried out when the subjects were taking these medications. The diagnosis was ascertained by a neurologist (RJR) on the basis of two of three cardinal signs - rigidity, bradykinesia, and resting tremor. The neurologist also screened patients for dementia using the Short Test of Mental Status. ${ }^{20}$ This test showed acceptable correlations with standardized tests of cognitive function, such as the Wechsler Adult Intelligence Scale, the Mattis Dementia Scale, and the Auditory Verbal Learning Test. With a cut-off score of 29 out of 38 , the sensitivity of this test in identifying dementia of the Alzheimer type is 86.4 with a specificity of $88.4 .{ }^{20}$ In the absence of information concerning its association with Parkinson's dementia, the selected cut-off score for inclusion in the present study was 35 .

Ten patients were excluded from the study because they were taking anticholinergic medication which has been found to interfere with free recall memory and paired-associate learning. ${ }^{21}$ This exclusion criterion has also been used by others (see Refs 22-24). Two PD subjects were excluded because they also suffered from arthritis. Finally, one subject was excluded because of confusion following a trial period on anticholinergic medication. Overall, 32 patients ( 18 men, 14 women) participated in the study. Six of them were taking only deprenyl, 25 were on levodopa, and nine were on bromocriptine (with or without levodopa). Only two subjects were not taking deprenyl, and this because of adverse reactions.

A comparison group consisting of 35 age- and educationmatched chronically disabled subjects was recruited. Criteria for inclusion in this group included: 1) the subject had a non-neurological progressive degenerative disease; 2 ) the disease was not abrupt in onset; 3 ) the resulting disabilities were not amenable to significant amelioration by rehabilitation; 4) the disease was generally free of psychiatric sequelae; and 5) therapy was symptomatic. Subjects suffering from osteoarthritis or rheumatoid arthritis generally fulfill these criteria. Arthritic subjects were recruited from an advertisement placed in a local newspaper, the Arthritis Society, a local arthritis self-support group, and with the aid of an orthopaedic surgeon. Three subjects were excluded from this group: one who was taking anticholinergic medication, one whose main problem was not with arthritis but of a respiratory nature, and one who had had previous brain surgery. Therefore, results are reported for 32 subjects (16 men, 16 women).

The control group was composed of individuals who were free of PD and who were not taking any medication for an 
arthritic condition. These subjects were recnuted from an advertisement placed in a local newspaper or were spouses of other subjects. Twelve men and 13 women were included in this group.

Eight subjects were left-hand writers (five in the PD group and three in the arthritic group), the remaining being right-handed.

\section{Materials}

Computer and software: A Zenith laptop portable microcomputer (Master 286 notebook) was used. Accessories included a Logitech mouse and a $35 \mathrm{~cm}$ monochrome video monitor (VGA, Zenith, model no. SMM-149P). The mouse was placed on rubber pads to prevent it from slipping. The image on the computer screen could be transferred to the monitor. The computer was used for both the paired-associate and the operant avoidance tasks.

Functional Disability: The Activities of Daily Living Scale ${ }^{25}$ measured subjective functional disability level. This scale has been used with both PD patients and with patients suffering from arthritis. ${ }^{26-27}$

Symptom Severity: Neurologic ratings of symptom severity and functional disability were based on the Hoehn and Yahr Stage ${ }^{28}$ and the Motor Examination Scale of the Unified Parkinson's Disease Rating Scale - Version 3.0. ${ }^{29}$

Paired-Associate Words: Six unrelated word pairs for the paired-associate task were selected randomly from the easier 20 pairs of the Underwood ${ }^{30}$ word pair pool. The pairs were as follows: crowd-photo, onion-banjo, embed-flute, zebra-gruff, thumb-comic, and totem-wives.

\section{Procedure}

Participation in the study was voluntary and informed consent was obtained from each subject. Evaluations of level of physical disability and of the severity of the parkinsonian symptoms were carried out separately prior to the testing session which lasted approximately one hour. However, evaluation of physical activity levels and testing were accomplished in a single session for the control group. All subjects were tested in their homes or at the University campus. During testing, subjects were sitting at a comfortable distance from the monitor.

Paired-Associate Task: Word pairs were presented on the computer screen during the study phase of the trials. During the recall phase, the cue word was presented singly on the monitor and subjects were instructed to recall the second word of the pair. All pair and cue word presentations were done in a random order. Pairs were presented successively for $3 \mathrm{sec}$ on the monitor. Subjects gave a verbal response which the investigator entered into the portable computer. Alternate study and recall trials continued until two successive perfect recalls were reached, up to a maximum of 10 recall trials. No feedback on performance was given to minimize the incentive component of the task. The number of correct responses for each trial was recorded.

Operant Avoidance Task: The operant avoidance task used to assess incentive learning was similar to that used by Cutmore and Beninger ${ }^{9}$, except for small changes to accommodate older subjects. The task consisted of discovering by trial-and-error a way to press the left button of the computer mouse to avoid losing money. Subjects made random patterns of button presses until they found one predetermined pattern that prevented money loss (i.e., avoidance response) or until $20 \mathrm{sec}$ had elapsed. Money was deducted from an initial amount of $\$ 10.00$ for each trial in which the avoidance response was not made (\$0.20 per incorrect trial) and until an escape response was made by pressing the right hand side button on the mouse $(\$ 0.03$ per sec up to a maximum of $\$ 0.15$ per trial). The avoidance response was made to prevent money loss by pressing the left button on the mouse whereas the escape response could be made by pressing the right button on the mouse to stop on-going money loss. The remaining amount of money appeared on the upper part of the screen.

An asterisk slowly crossed the bottom of the screen from left to right throughout each trial. Visual feedback on rate of responding was provided in the form of colons spread out along the trajectory of the asterisk. A high rate of responding placed the colons close together whereas responding at a slower pace spread them out.

As in the Cutmore et al. ${ }^{9}$ task, two preprogrammed patterns were to be discovered. The first was a differential reinforcement for low rate of responding (DRL) on which subjects had to produce nine consecutive presses with time intervals in between presses of at least $1 \mathrm{sec}$. The other contingency consisted of a differential reinforcement for high rate of responding (DRH) which was satisfied by 16 consecutive presses that were at most $0.5 \mathrm{sec}$ apart. In other words, how slowly or quickly a subject pressed on the button determined success or failure in finding the two preprogrammed patterns. Two trials were presented on the DRL schedule followed by two trials on the DRH schedule, and so on, alternating in pairs. A message on the monitor informed subjects as to which contingency, A or B, was in effect. Subjects were allowed $20 \mathrm{sec}$ to discover or satisfy the contingency. A successful response terminated a trial and prevented money loss (avoidance response). When the contingency was not satisfied within $20 \mathrm{sec}$, the amount of money started to go down. This was indicated on the computer screen by flashing the decreasing amount of money and the asterisk disappearing from the screen. Further loss of money could be prevented by making an escape response within five sec, terminating a trial. At the end of the five sec interval, the amount of money stopped flashing and the trial was automatically terminated even if no escape response had been made. A total of 32 trials was given. The number of trials correct (in which an avoidance response has been made), the proportion of escape responses made on incorrect trials, and escape latencies were recorded.

In order to assess the physical ability of participants to meet the DRH contingency, all those who had failed in making at least one avoidance response in the DRH schedule were asked to button press as fast as they could for $20 \mathrm{sec}$, at the end of the operant task (data recorded only as "passed" or "failed").

All subjects were given the paired-associate task followed by the operant avoidance task on which money was earned. At the end of this task, subjects were paid the amount of money left on the screen or a minimum of $\$ 4.00$. Subjects were debriefed and thanked for their participation.

\section{Results}

\section{Subject Characteristics}

Subject characteristics are summarized in Table 1. No significant difference was found among the groups on age and education level. The PD and the arthritic groups did not differ 
Table 1. Subject Characteristics.

\begin{tabular}{lccc}
\hline & Control & Arthritis & PD \\
\hline Sample Size & 25 & 32 & 32 \\
Age & 66.5 & 66.1 & 66.8 \\
& $( \pm 7.6) \dagger$ & $( \pm 6.8)$ & $( \pm 6.8)$ \\
Education Scale ttt & 3.7 & 3.8 & 4.3 \\
& $( \pm 1.5)$ & $( \pm 1.3)$ & $( \pm 1.4)$ \\
Grade Equivalent & 12.4 & 12.2 & 11.7 \\
ADL* Score & 24.2 & $34.0+t$ & $36.0+\dagger$ \\
& $( \pm 0.8)$ & $( \pm 13.2)$ & $( \pm 12.2)$ \\
Yrs since Diagnosis & & & 5.1 \\
& & & $( \pm 4.1)$ \\
UPDRS ** & & & 11.8 \\
& & & $( \pm 8.1)$ \\
Hoehn \& Yahr Stage*** & & & 2 \\
I & & & 17 \\
II & & 11 \\
III & & \\
Medication (mg/day) & & & $( \pm 283)$ \\
L-Dopa/Carbidopa & & & 5.6 \\
Bromocriptine (mg/day) & & & $( \pm 10.1)$ \\
\hline
\end{tabular}

* ADL stands for the Activities of Daily Living scale.

** Unified Parkinson's Disease Rating Scale Version 3 - Motor Examination subscale only

*** Two PD subjects could not be assessed on this scale.

$+\quad$ Numbers in parentheses are standard deviations.

t† Significantly different from control ( $p<0.01$, ANOVA)

t+t The Education Scale ${ }^{43}$ was as follows:

\begin{tabular}{lc} 
Years & Code \\
$>16$ & 1 \\
16 & 2 \\
$13-15$ & 3 \\
12 & 4 \\
$10-12$ & 5 \\
$7-9$ & 6 \\
$0-6$ & 7 \\
\hline
\end{tabular}

significantly on the Activities of Daily Living Scale ( $p>0.05$, analysis of variance [ANOVA]) suggesting that the two groups were similar in self-rated physical disability. As expected, the control group was significantly less impaired physically than the other two groups combined $(\mathrm{p}<0.01$, ANOVA).

\section{Paired-Associate Task}

Twelve out of 29 subjects $(41 \%)$ in the PD group achieved the criterion of two consecutive correct recall trials prior to or at the tenth trial; corresponding proportions were 17 out of 28 (61\%) and 13 out of $25(52 \%)$ for the arthritic and control groups, respectively. The differences among the groups were not statistically significant $\left(\chi^{2}=2.21, \mathrm{p}=0.34\right)$. Subjects who achieved the criterion in fewer than 10 trials were assigned the maximum score for all remaining trials. The arthritic group obtained the highest number of correct responses, and the PD group, the lowest (see Figure 1). A mathematical model based on performance at each trial provided a learning index and an

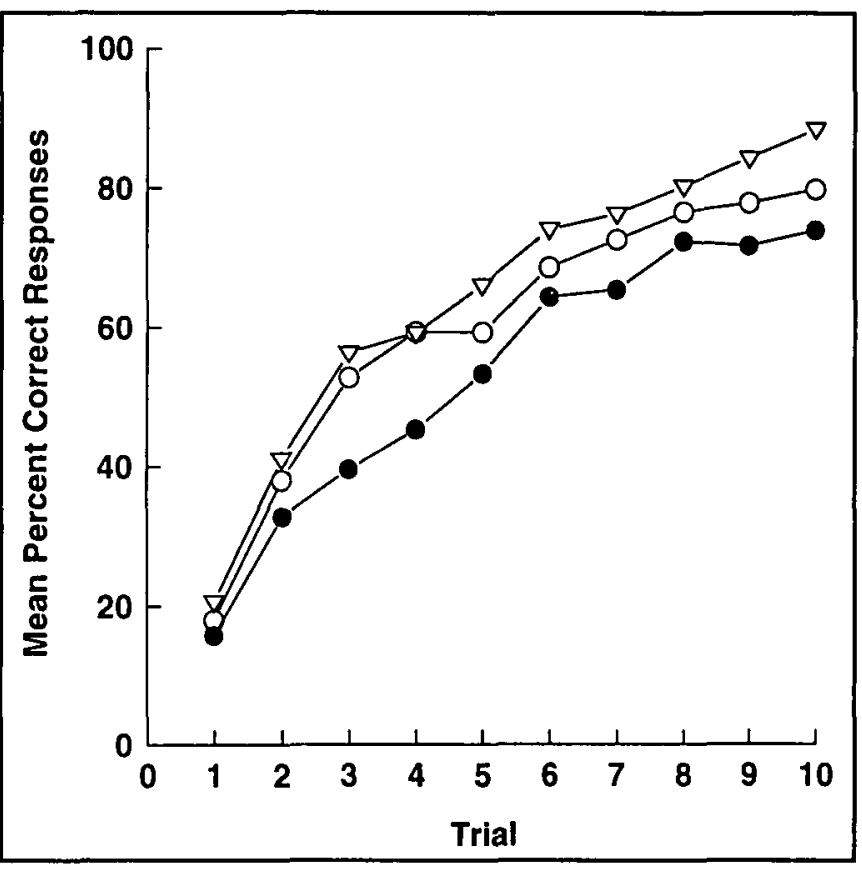

Figure 1: Paired Associate Task: Mean percent correctly recalled response words as a function of trial.

Symbols: o: control group; $\nabla$ : arthritic group; Parkinson's disease group.

asymptotic value for each subject. This model is described by the following equation:

$$
\mathrm{Y}=\mathrm{B} *\left(1-\mathrm{e}^{(-\mathrm{kt})}\right)
$$

where $Y=$ Number of correct recall responses.

$$
\begin{aligned}
& \mathrm{B}=\text { Asymptotic value. } \\
& \mathrm{k}=\text { Rate of change (Learning Index). } \\
& \mathrm{t}=\text { Trial number. }
\end{aligned}
$$

An asymptotic value much higher than 6 indicates a learner who would have necessitated many trials to achieve a stable performance. The higher the learning index, the faster a subject learned the words to be recalled. Table 2 lists the group medians and interquartile ranges for the learning index and asymptotic value. These results indicate a better performance of the arthritic group, as revealed by a higher learning index and an asymptotic value closest to 6 .

To estimate how well the model matched the empirical data, standard methods of closeness of fit index were used for each subject. This index reflects the extent to which an individual performance can be accurately expressed by the model. Group medians on the closeness of fit index indicated an acceptable degree of model fit for each group (see Table 2).

A nonparametric test was used due to a marked lack of normality in the data. The rank order Mann-Whitney $U$ test was performed twice for the three computed measures: firstly, the arthritic group was compared to the control group, and no significant difference was found. Therefore, these two groups were combined given that there is no reason to believe that a difference should exist. Secondly, the PD group was compared with the combined control and arthritic groups. None of these comparisons was statistically significant on any of the three parameters. That is, group differences in learning parameters were not significant on the paired-associate task (learning index: $p=0.42$ and $p=0.40$; asymptote: $p=0.92$ and $p=0.76$, respectively). 
Table 2. Learning Parameters for the Paired-Associate Task.

\begin{tabular}{lccccccc}
\hline & & \multicolumn{2}{c}{ Learning Index } & \multicolumn{2}{c}{ Asymptote } & \multicolumn{2}{c}{ Fit Index } \\
Group & $\mathbf{n}$ & Median & Range & Median & Range & Median & Range \\
\hline Control & 25 & 0.25 & $(0.0-39.9)$ & 6.59 & $(1.4-1437)$ & 0.77 & $(0.27-0.94)$ \\
Arthritis & 28 & 0.36 & $(0.0-1.8)$ & 6.22 & $(0.4-2492)$ & 0.85 & $(0.02-0.96)$ \\
Parkinson & 29 & 0.19 & $(0.0-2.1)$ & 6.74 & $(0.2-1016)$ & 0.79 & $(0.00-0.96)$ \\
\hline
\end{tabular}

Furthermore, group differences in the closeness of fit of the model were not significant ( $p=0.30$ and $p=0.51$, respectively).

\section{Operant Avoidance Task}

Avoidance responses and escape responses were examined separately.

Avoidance Responses: All participants were able to meet the DRH requirement of an inter-response time not exceeding 0.5 sec (no data shown). Figure 2 illustrates the percentage of trials in which a successful avoidance response was made as a function of blocks of four trials. The PD group performed the worst on the slow responding schedule (DRL) and the arthritic group was the least successful on the fast responding schedule (DRH). Amount of learning is indicated by the magnitude of improvement from the first to the fourth block; in this regard, the PD group did worst on both schedules.

A split-plot ANOVA based on mean percent trials in which an avoidance response was made with Group as between factor and Schedule and Blocks of trials as within factors revealed a significant Group X Block (linear) interaction $(p<0.05)$. This represented the highest order interaction, and only significant interaction, in which the factor group was involved. The non-linear components of the interaction, quadratic and cubic, were not significant ( $p=0.73$ and $p=0.08$, respectively). The linear component was isolated for each subject using a linear regression that provided a slope (unstandardized B) and a percent variance accounted for $\left(R^{2}\right)$. In the absence of learning, as in four successful avoidance responses or four failures to avoid in each of the four blocks of trials, the slope (or learning index) was given the value of zero. Learning indices were $0.18 \pm 0.44( \pm$ $\mathrm{SD}$; range $0.00-1.49$ ), $0.37 \pm 0.49$ (range $0.00-1.09$ ), and 0.09 \pm 0.36 (range $0.00-0.43$ ) for the DRL schedule and $0.45 \pm 0.56$ (range $0.00-1.49$ ), $0.42 \pm 0.64$ (range $0.00-1.49$ ), and $0.16 \pm$ 0.54 (range $0.00-1.55$ ) for the DRH schedule, for the control, arthritic, and PD groups, respectively. In all three groups, learning was better in the fast responding schedule (DRH) than in the slow-paced schedule (DRL). The PD group had the lowest learning index on both schedules.

A two-way mixed ANOVA, with Group as between factor and Schedule as within factor, performed on the learning index indicated only one significant effect, that of Group ( $p<0.05$ ). Planned comparisons further revealed that the control and arthritic groups did not differ significantly from each other ( $p=$ 0.44 ) and were therefore combined. However, the PD group did not learn the operant avoidance task as well as the other two groups taken together $(p<0.01)$. No main effect or interaction was significant on the closeness of fit index of the linear model, suggesting that the model used is equally appropriate for all groups.

Escape Responses: Another aspect of interest in the operant

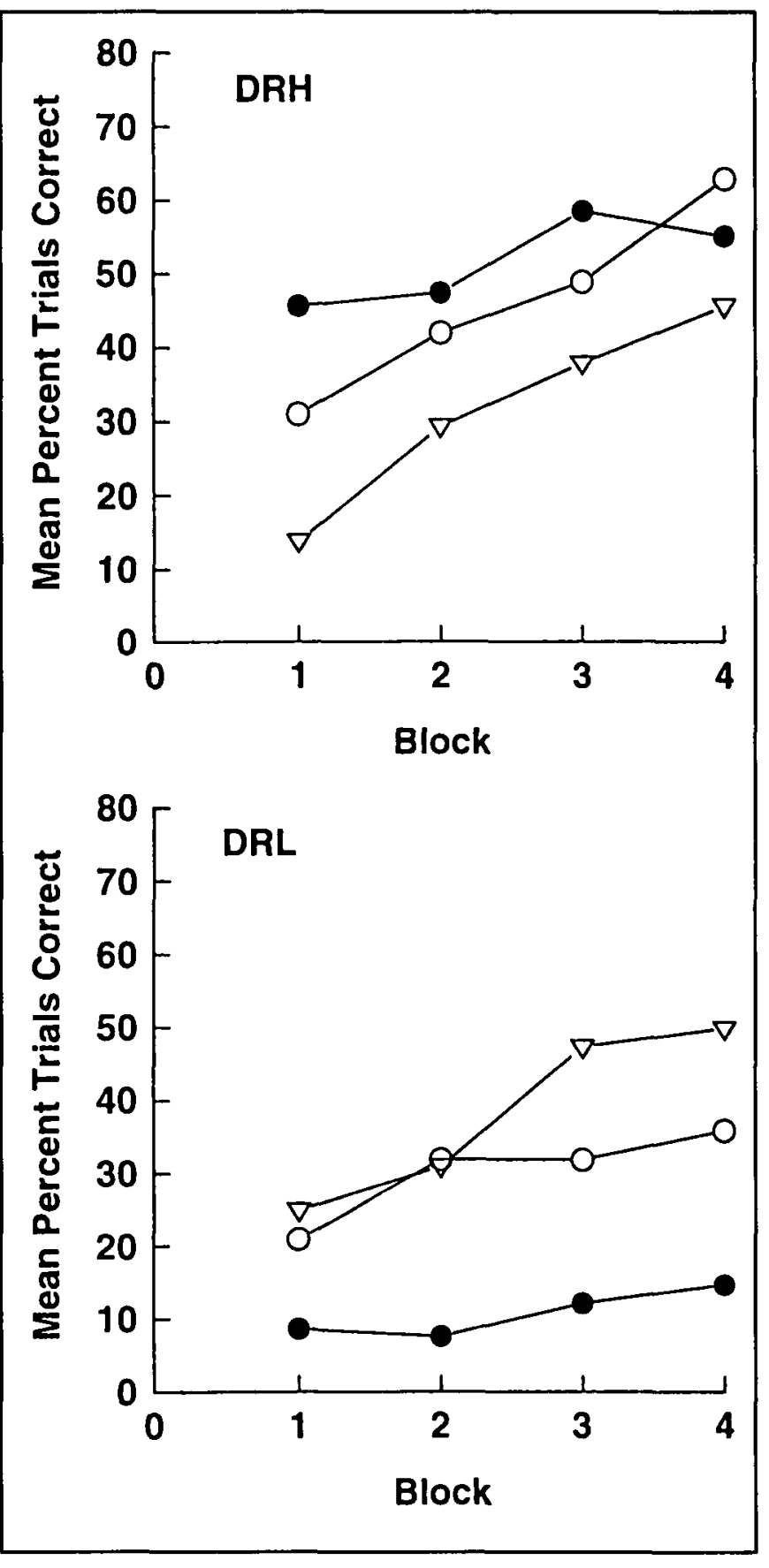

Figure 2: Operant Task: Mean percent trials on which a successful avoidance response occurred as a function of blocks of trials for each schedule separately.

Symbols: o: control group; $\nabla$ arthritic group: Parkinson's disease group. 
avoidance task concerned escape responses. The median values of the percentage of escape responses made on incorrect trials were 93.8 (range 26\% - 100\%), 93.3 (range 15\% - 100\%), and 96.8 (range 30\% - 100\%) for the PD, arthritic, and control groups, respectively. The Mann-Whitney $U$ test was used because the distribution of scores was heavily skewed. Because escape responses were expected to reflect motor dysfunction, the PD group was compared separately to the arthritic and control groups. PD subjects made significantly fewer escape responses than the control subjects $(p<0.05)$, but their performance was comparable to that of the arthritic subjects $(p=0.53)$.

An ANOVA done on escape latencies failed to reveal any significant group differences $(p=0.26)$. The Trial by Group interaction was also non significant $(p=0.22)$. The mean escape latencies (in $\mathrm{msec}$ ) for the PD, arthritis, and control groups were $2512 \pm 948 \mathrm{msec}( \pm \mathrm{SD}$; range $330-5000 \mathrm{msec}), 2507 \pm 1120$ $\mathrm{msec}$ (range $160-5000 \mathrm{msec}$ ), and $2116 \pm 838 \mathrm{msec}$ (range 220 - $5000 \mathrm{msec}$ ), respectively.

\section{Discussion}

The results of the present study are consistent with the possibility of a differential involvement of dopaminergic systems in different types of learning despite dopaminergic replacement in patients with PD. It was hypothesized that stimulus-stimulus associative learning does not involve dopaminergic systems whereas incentive learning, the acquisition by reward-related stimuli of the ability to control responding, may depend on intact dopaminergic neuronal activity. ${ }^{1,2}$ Two predictions were confirmed based on these hypotheses: first, PD subjects who performed normally on a word paired-associate task were impaired on an operant avoidance task relative to individuals without a dopaminergic neurodegenerative disorder. Secondly, the impairment was noted on avoidance responses, but not on escape responses. These results suggest that the PD subjects had an impairment of incentive learning - or habit learning ${ }^{14}$ - that was not attributable to a motor dysfunction.

In the present study, group differences in the word pairedassociate task were not significant. It could be argued that the word-pairs used were too easy to detect any difference that may exist among the groups. Although this is possible, it is unlikely. Indeed, a similar task of comparable difficulty revealed a significant difference in performance between controls and schizophrenics which correlated with the degree of thought disorder but not of dopamine dysfunction. ${ }^{9}$ It is difficult to compare the current results with those in the literature because of differences in word list used, feedback on performance or lack thereof, and modality of stimulus presentation - auditory versus visual. In spite of these differences, the present results are in agreement with others that failed to indicate a significant difference between PD subjects and healthy controls on the Wechsler Memory Scale paired-associate task. . $^{31-33}$ In contrast, others found that PD subjects were impaired on a sound form association test. ${ }^{24}$ However, the latter subjects were not screened for dementia. Karayanidis ${ }^{34}$ has suggested that the performance of non-demented and non-confused PD patients is not impaired on a word-paired associate task. In other words, impaired performance on a task assessing stimulus-stimulus associative learning is not an inevitable consequence of $\mathrm{PD}$, but rather appears to be a consequence of dementia. This is consistent with the suggestion of Pillon et al..$^{35}$ that performance on the Wechsler paired-associate task may be independent of dopaminergic dysfunction because it does not correlate with the severity of akinesia and rigidity. Therefore, immediate recall of simple associations remains relatively intact in non-demented PD subjects.

PD subjects were impaired on the operant avoidance task relative to the two comparison groups in terms of number of avoidance responses. The principles of operant conditioning suggest that the identification of a pattern that turns off an aversive stimulus would lead to an increased tendency to select that pattern again. This was true for the arthritic and control subjects, but not for the PD subjects. The observed deficit was unrelated to physical limitations per se because all subjects who failed in the fastresponding schedule were able to satisfy the contingency at the end of the task, when asked to press the button as fast as possible (data not shown).

Furthermore, as expected, when loss of money became apparent on the computer screen at the end of incorrect trials, $P D$ subjects were not significantly less adept at making an escape response than were comparison subjects. In addition, the proportion of escape responses made on incorrect trials did not differ statistically between PD and arthritic subjects. Fatigue and/or inattention may have been responsible for the significantly lower percentage of escape responses made on incorrect trials by both the PD and arthritic groups relative to the control group. Because fatigue and inattention are not exclusive to the PD group, however, they cannot be attributed to the disease itself. Rather, they may have been the consequence of a chronic physical impairment or some other factor. The selection of control groups in studies involving patients with PD is important in order to separate the neurochemical effects of the disease from other effects not specific to PD.

A limitation of the present study concerns the floor effect noted in the money loss avoidance task for the PD group. This floor effect prevented the computation of correlations between performance on this task, on the one hand, and severity of motor dysfunction and medication dosage, on the other hand. One possible reason that PD subjects performed so poorly on the avoidance task, other than a deficit in incentive learning, concerns the ability to time oneself. Indeed, appropriate timing of button presses was the key to successful avoidance responses. PD may interfere with the ability to maintain a steady rate of button presses ${ }^{36}$ However, it may be argued that, in the present task, the timing criterion was flexible because the required inter-response intervals for the avoidance responses laid above or below predetermined time values and the trial duration was sufficiently long to allow for some inconsistency in button pressing without penalty. Therefore, the extent to which a disturbance in the timing of movements may have interfered with the performance of avoidance responses may have been limited.

In summary, the poor performance of PD subjects on the avoidance responses may be attributable to an impairment in incentive learning rather than to a motor impairment. The nonhuman mammalia literature suggests that incentive learning may depend on intact dopaminergic systems in the brain. ${ }^{1,2}$ Results from other studies involving the use of an avoidance paradigm with human subjects treated with neuroleptics are consistent with a role for dopamine in incentive learning. ${ }^{8}{ }^{818,19}$ 
Physiological studies on primates have demonstrated that dopaminergic neurons in the nigrostriatal and mesolimbic systems display bursting patterns of depolarizing activity, instead of single spikes, in response to a reward, such as food ${ }^{37}$ When a stimulus is paired consistently with the delivery of a reward (as in conditioning), this transient dopaminergic patterned response gradually shifts from the reward to the stimulus that signals the imminent delivery of the reward. ${ }^{37}$ These transient increases in nigrostriatal dopaminergic influence on the striatum may be responsible for the internal regulation of responses to external stimuli that signal rewards.

If, as suggested in the present paper, the patterned activity of the nigrostriatal dopaminergic neurons contributes to the activation of responses to environmental stimuli that signal rewards, then a reduced patterned activity would interfere with the facilitation of such responses. In the latter case, striatal output to the premotor cortex (via the motor loop) and/or to the frontal association cortex (via the "complex" loop) may be inappropriate to initiate the cascade of commands necessary for the initiation, execution and/or automation of a motor response to significant environmental stimuli.

In PD, progressive nigrostriatal degeneration involves both the loss of endogenous dopamine as well as the loss of normal physiological function and modulation of the nigrostriatal system. Dopamine replacement therapy would not be expected to significantly alter the intrinsic physiological function and regulated release of dopamine by residual nigrostriatal neurons in response to stimuli that signal rewards, even in a setting of maximal anti-parkinsonian effectiveness as measured by quantitative clinical scales (see Ref 38). To the extent that incentive learning depends on the modulation of nigrostriatal function, operant avoidance tasks may be used to examine whether the phasic dopaminergic response to incentive stimuli is retained in early untreated Parkinson's disease and whether this response is maintained when the system is assisted by replacement dopamine. A better performance of the patients in the untreated condition would suggest that dopamine replacement is ineffective in restoring the phasic signals necessary for incentive learning to occur. Indeed, if the dopamine dose is too high, there could be tonic activation - indicated by an improvement of parkinsonian symptoms - but the phasic signal may be masked - indicated by impaired incentive learning. Furthermore, as the dopaminergic neurons continue to degenerate, they would gradually lose their ability to send transient dopaminergic signals in response to incentive stimuli. Therefore, dopamine replacement therapy may be ineffective in reversing incentive learning difficulties at all stages of the disease. Excessive incentive learning, on the other hand, may result from excessive phasic responses and may contribute to the development of inappropriate responses to objects or people, similar to some behaviors observed in schizophrenia.'

Taylor et al. ${ }^{32}$ have argued that the cognitive impairment observed in PD arises principally from the disruption of frontal lobe functioning due to the combined disturbances of two systems, namely a perturbed outflow from the striatum and a reduced availability of cortical dopamine. Based on the necessity to generate a plan to resolve the operant avoidance task, the frontal lobe hypothesis would predict a deficit in PD subjects. The deficit may or may not be aggravated by the alternating contingency schedule (DRL and DRH), which required mental set shifting. Although based on a different conceptual framework, the present study may complement these conclusions regarding the involvement of the striatum and extend them by implicating the nigral influence on striatal function as one mechanism subserving incentive learning. Thus, the loss of nigrostriatal dopamine neurons in PD subjects may result in a loss of the ability of reward-related stimuli to influence responses. This would alter striatal output and, therefore, frontal cortical input. In this way, dysfunction in the nigrostriatal system may contribute to dysfunction in the frontal cortex.

Several studies have identified some impairments in procedural learning in individuals with PD using different types of tasks (see Refs $24,39,40$ ). The present findings are consistent with a possible primary role of the nigrostriatal dopaminergic system in incentive learning and are in agreement with the hypothesis of Phillips and Carr ${ }^{16}$ that dopamine is involved in some manner in procedural learning. The ability to learn depends on the integrity of the memory systems. Declarative memory, the conscious recollection of facts and events, on the other hand, appears to depend on structures other than the striatum..$^{41}$ This does not imply that declarative memory remains intact in PD. In fact, some argue that declarative memory is impaired in PD (see Refs 24,39 ).

The concept of a dissociation between procedural and declarative memory systems in PD is not new. For instance, PD subjects in a study by Saint-Cyr et al. ${ }^{40}$ were deficient on a modified version of the Tower of Hanoi task but their recall and recognition abilities on other tests were preserved. The present paper is the first report of a deficit in avoidance incentive learning in PD.

The present study addresses new incentive learning in PD, as opposed to old incentive learning. The proposed hypothesis regarding the role of dopamine in incentive learning suggests that a dopaminergic dysfunction is likely to interfere in the acquisition phase of new incentive learning whereas it would conceivably trigger the extinction phase of old incentive learning. For instance, akinetic animals that have stopped responding to new incentive stimuli will still respond to conditioned incentive stimuli that have not yet extinguished. ${ }^{42}$ Similarly, it is possible that PD patients in the late stages of the disease could respond to conditioned stimuli that have not yet extinguished, such as old photographs of family members, old friends not seen for a long time, or old songs not heard for a while. However, with repeated presentations of these stimuli, extinction would occur, and the patient would stop responding.

There remain several unanswered questions regarding incentive learning and PD. These include identification of the external stimuli or events that trigger a patterned activity in the dopaminergic neurons that are degenerating in PD and a determination of what constitutes sufficient reward in humans. The present findings suggest that pursuit of this area of research may have implications for cognitive rehabilitation.

\section{ACKNOWLEDGEMENTS}

DC was supported by a MRC Studentship. We thank Mr. Martin York for development of computer software and Dr. Stuart Lawson for assistance with the statistical analysis. Mrs. Sandy Weatherby (Movement Disorders Clinic, Queen's University/Kingston General Hospital) and Mrs. Tracy McGee are acknowledged for their assistance in recruiting subjects with $\mathrm{PD}$ and arthritis, respectively. 


\section{REFERENCES}

1. Beninger RJ. The role of dopamine in locomotor activity and learning. Brain Res Rev 1983; 6: 173-196.

2. Beninger $\mathrm{RJ}$. Role of $\mathrm{D}_{1}$ and $\mathrm{D}_{2}$ receptors in learning. In: Waddington J., ed. Dopamine Receptor Interactions. London: Acadmic Press, 1993; 115-157.

3. Anisman H, Irwin J, Zacharko RM, Tombaugh TH. Effects of dopamine receptor blockade on avoidance performance: assessment of effects on cue-shock and response-outcome associations. Behav Neural Biol 1982; 36: 280-290.

4. Beninger RJ. Methods for determining the effects of drugs on learning. In: Boulton AA, Baker GB, Greenshaw AJ, eds. NeuroMethods, Volume 13: Psychoparmacol. Clifton: The Humana Press, 1989: 623-685.

5. Fibiger HC. The neurobiological substrates of depression in Parkinson's disease: a hypothesis. Can J Neurol Sci 1984; 11 : 105-107.

6. Beninger RJ, D'Amico CM, Ranaldi R. Microinjections of flupenthixol into the caudate-putamen of rats produce intrasession declines in food-rewarded operant responding. Pharmacol Biochem Behav 1993; 45: 343-350.

7. Beninger RJ, Ranaldi R. Microinjections of flupenthixol into the caudate-putamen but not the nucleus accumbens, amygdala or frontal cortex of rats produce intra-session declines in foodrewarded operant responding. Behav Brain Res 1993; 55: 203212.

8. Koob GF, Simon H, Herman JP, LeMoal M. Neuroleptic-like disruption of the conditioned avoidance response requires destruction of both the mesolimbic and nigrostriatal dopamine systems. Brain Res 1984; 303: 319-329.

9. Cutmore TRH, Beninger RJ. Do neuroleptics impair learning in schizophrenic patients? Schiz Res 1990; 3: 173-186.

10. Fantie BD, Kosmidis MH 1994. Avoidance responding and closedhead injury: replication and reevaluation of the "anticipatory behaviour deficit". Clin Neuropsychol 1995; 8: 379-387.

11. Weiner $H$. Response cost and the aversive control of human operant behavior. J Exp Anal Behav 1963; 6: 415-421.

12. Weiner $H$. Modification of escape responding in humans by increasing the magnitude of an aversive event. J Exp Anal Behav 1964; 7: 277-279.

13. Beninger RJ. The role of serotonin and dopamine in learning to avoid aversive stimuli. In: Archer $\mathrm{T}$ and Nilsson LG, eds. Aversion, Avoidance and Anxiety: Perspectives on Aversively Motivated Behaviour. Hillsdale NJ: Lawrence Erlbaum Assoc, 1989: 265-284.

14. Salmon DP, Butters N. Neurobiology of skill and habit learning. Curr Opin Neurobiol 1995; 5: 184-190.

15. Squire LR. Declarative and nondeclarative memory: multiple brain systems supporting learning and memory. J Cog Neurosci 1992; 4: $232-243$.

16. Phillips AG, Carr GD. Cognition and the basal ganglia: a possible substrate for procedural knowledge. Can J Neurol Sci 1987; 14 : 381-385.

17. Robbins TW. Cognitive deficits in schizophrenia and Parkinson's disease: neural basis and the role of dopamine. In: Willner P, Scheel-Kruger J, eds. The Mesolimbic Dopamine System: From Motivation to Action. Chichester: Wiley \& Sons, 1991: 497-528.

18. Fischman MW, Schuster CR. The effects of chlorpromazine and pentobarbital on behavior maintained by electric shock of point loss avoidance in humans. Psychopharmacol 1979; 66: 3-11.

19. Fischman MW, Smith RC, Schuster CR. Effects of chlorpromazine on avoidance and escape responding in humans. Pharmacol Biochem Behav 1976; 4: 11-114.

20. Kokmen E, Smith GE, Petersen RC, Tangalos E, Ivnik RC. The short test of mental status: correlations with standardized psychometric testing. Arch Neurol 1991; 48: 725-728.
21. Koller WC. Disturbance of recent memory function in Parkinsonian patients on anticholinergic therapy. Cortex. 1984; 30: 307-311.

22. Huber SJ, Freidenberg DL, Shuttleworth EC, Paulson GW, Christy JA. Neuropsychological impairments associated with severity of Parkinson's disease. J Neuropsychol Clin Neurosci. 1989; I: 154-158.

23. Pillon B, Dubois B, Ploska A, Agid Y. Severity and specificity of cognitive impairment in Alzheimer's, Huntington's, and Parkinson's diseases and progressive supranuclear palsy. Neurology. 1991; 41: 634-643.

24. Allain H, Lieury A, Quemener V, et al. Procedural memory and Parkinson's Disease. Dementia 1995; 6: 174-178.

25. Gotham AM, Brown RG, Marsden CD. Depression in Parkinson's disease: a quantitative and qualitative analysis. J Neurol Neurosurg Psychiatry 1986; 49: 381-390.

26. Brown RG, MacCarthy B, Jahanshahi J, Marsden CD. Accuracy of self-reported disability in patients with Parkinsonism. Arch Neurol 1989; 46: 955-959.

27. Ehmann TS, Beninger RJ, Gawel MJ, Riopelle RJ. Depressive symptoms in Parkinson's disease: a comparison with disabled control subjects. J Geriat Psychiat Neurol 1990; 5: 3-9.

28. Hoehn MM, Yahr MD. Parkinsonism: onset, progression, and mortality. Neurology 1967; 17: 427-442.

29. Fahn S, Marsden CD, Jenner P, Teychenne P. Recent developments in Parkinson's disease. New York: Raven Press, 1987.

30. Underwood BJ. Paired associate learning: data on pair difficulty. Mem Cog 1982; 10:610- 617

31. Mohr E, Juncos J, Cox C, et al. Selective deficits in cognition and memory in high-functioning Parkinsonian patients. J Neurol Neurosurg Psychiatry 1990; 53: 603-606.

32. Taylor AE, Saint-Cyr JA, Lang AE. Frontal lobe dysfunction in Parkinson's disease. Brain 1986; 109: 845-883.

33. Taylor AE, Saint-Cyr JA, Lang AE. Cognitive changes in relation to treatment response. Brain 1987; 110:35-51.

34. Karayanidis F. Parkinson's disease: a conceptualization of neuropsychological deficits within an information-processing framework. Biol Psychol 1989; 29: 149-179.

35. Pillon B, Dubois B, Cusimano G, et al. Does cognitive impairment in Parkinson's disease result from non-dopaminergic lesions? J Neurol Neurosurg Psychiatry 1989; 52: 201-206.

36. Freeman JS, Cody FWJ, Schady W. The influence of external timing cues upon the rhythm of voluntary movements in Parkinson's disease. J Neurol Neurosurg Psychiatry 1993; 56 : 1078-1084.

37. Romo R, Schultz W. Dopamine neurons of the monkey midbrain: contingencies of responses to active touch during self-initiated arm movements. J Neurophysiol 1990; 63: 592-606.

38. Divac I, Oberg GE, Rosenkilde CE. Patterned neural activity: implications for neurology and neuropharmacology. In: Schneider FS, Lidsky TI, eds. Basal Ganglia and Behavior: Sensory Aspects of Motor Functioning. Toronto: Hans Huber Publishers, 1987: 61-67.

39. Heindel WC, Salmon DP, Shults CW, Walicke PA, Butters N. Neuropsychological evidence for multiple implicit memory systems: a comparison of Alzheimer's, Huntington's, and Parkinson's Disease patients. J Neurosci 1989; 9: 582-587.

40. Saint-Cyr JA, Taylor AE, Lang AE. Procedural learning and neostriatal dysfunction in man. Brain 1988; 111 : 941-959.

41. Squire LR, Zola-Morgan S. Memory: brain systems and behavior. Trend Neurosci 1988; 11: 170-175.

42. Franklin KBJ, McCoy SN. Pimozides-induced extinction in rats: stimulus control of responding rules out motor deficit. Pharmacol Biochem Behav 1979; 11: 71-75.

43. Murrell S, Himmelfarb S, Schulte P, Norris F. Pretest of candidate measures: results and final decision. Louisville: University of Urban Studies Center, 1985. 